\title{
ADDRESSING MARITIME INDUSTRY FEEDBACK FOR CONTINUOUS IMPROVEMENT: A PROCESS MODEL
}

\author{
Emeliza T. Estimo, Geneveve M. Aguilar \\ John B. Lacson Colleges Foundation (Philippines)
}

\begin{abstract}
Stakeholders' satisfaction is essential for sustainability. It provides opportunities for learning the strengths and weaknesses of an institution or organization to design and improve the quality of its services to promote goodwill and effective partnerships with the industry and the community. This descriptive study discusses and illustrates how a leading maritime university implements a process model for addressing industry feedback in the Philippines based on a trend of data gathered for nine consecutive years $(2011-2019)$. This paper also mentions the actions taken by the University to address the issues and concerns raised by the industry stakeholders represented by shipping company Presidents, Crewing Managers, and Training Officers, particularly on the quality of graduates that it produces vis-à-vis the expectations of the industry. This study used the mixed methods of gathering data. The results revealed a trend in the level of satisfaction of the industry stakeholders, which point to a consistently high level of satisfaction with minimal declines at certain points from the quality of students that the school is producing to the quality of services provided over the years. Certain factors have been discussed as possibly influential in the decline of the stakeholders' level of satisfaction. After implementing the work processes to address industry feedback, it was found to be working well and is now being considered by the administration as one of its best practices. To date, the University is continuously maximizing all strategies possible to sustain its performance in meeting the industry's expectations.

Keywords: Maritime university; stakeholders' satisfaction; industry feedback; process model; industry expectations
\end{abstract}

\section{Introduction}

Surveys on stakeholders' satisfaction give people some say over how projects or policies may affect their lives. It is essential for sustainability. (Fonseca et al. 2016) It provides opportunities for learning the strengths and weaknesses of an organization to design and improve its services to promote goodwill and effective partnerships with the stakeholders. The stakeholders in organizational effectiveness models are 
usually defined as owners, employees, customers, creditors, suppliers, and people in the distribution network to whom company owners and shareholders have the binding obligation to satisfy. (Freeman 2015; Ackermann et al. 2011). They include people or small groups with the power to respond to, negotiate with, and change their strategic future. In ensuring quality management, measuring the level of satisfaction in terms of quality must include that of the most important stakeholders. (Grudowski et al. 2015) Stakeholders may affect the organization and, in turn, be affected by the organization's actions, policies, practices, and decisions. (Fassin 2009)

The stakeholders of John B. Lacson Foundation Maritime University, a leading maritime university in the Philippines, include its employees, the students it serves, the shipping industry, the parents, and the alumni. To ensure that the stakeholders' expectations are met, annual assessments and intervening measures are done to sustain excellence in the students' academic performance. Faculty and non-teaching staff are being evaluated by their Subject Area Heads and Program Heads, Deans, and even the Administrators to monitor and implement quality education through instruction and research. Parents occasionally visit the school to check on their children and transact with certain offices such as the Dean's Office, the School Clinic, the Registrar's Office, the Accounting Office, and the SPS Office. Students benefit from the services of their teachers and the departments or offices with which their everyday activities are associated. The alumni hold some degree of satisfaction while looking at their preparedness for the real world. By evaluating themselves in line with their actual work onboard their vessels, they could tell whether their Alma mater had been successful enough in educating and preparing them to face the realities of life. Their level of satisfaction with the services rendered by the school could speak of whether they had been served well or not.

The significant contribution of the feedback coming from the stakeholders cannot be denied. It serves as a clear indicator of the universities' performance as quality education providers and other related services. For maritime institutions, feedback from stakeholders, particularly those in the job market, is important for sustaining pro-quality undertakings in providing quality education. (Ulewicz 2017) To ensure customers' expectations, universities need to obtain constant feedback from all sectors they serve and ensure appropriate actions are taken to address the gathered feedback.

This investigation focuses on the feedback gathered from the shipping industry stakeholders of JBLFMU and how their inputs are addressed through a process model that the University has implemented since 2011.

\section{Objectives}

This descriptive study discusses and illustrates how a process model addressing industry feedback is implemented by a leading maritime university in the Philippines, based on a trend of data gathered for nine consecutive years. This 
paper also mentions what actions were taken by the University to address the issues and concerns raised by the industry stakeholders, represented by shipping company Presidents, Crewing Managers, and Training Officers, particularly on the quality of graduates vis-à-vis the expectations of the industry. Specifically, this study was done to address the following questions:

1. What is the level of satisfaction of the shipping company stakeholders with the quality of graduates of the University from 2011 to 2019 ?

2. What issues and concerns were commonly expressed by the industry stakeholders in their feedback?

3. What factors contribute to the decline in stakeholders' satisfaction based on related literature, and how are these factors viewed in the context of the University?

4. What plans of action were done to address the issues and concerns raised by the industry stakeholders?

5. What process model can be proposed to address the common issues and concerns raised by the shipping industry stakeholders?

\section{Theoretical Framework}

Freeman's Stakeholders' Theory posits that the stakeholders are vital to the survival and success of the organization. (Freeman 2015) This theory advances the idea that service providers must identify strategies or measures to satisfy their stakeholders. The moral view of this theory suggests that those impacted by an organization's operations have a right to be informed and demand certain performance standards (Freeman 2015), indicating a balancing of interests and benefits. The strategic view states that businesses or entities should value the opinions and feedback coming from their stakeholders. What they do as a team must be geared towards the interest of their customers or clients.

Dr. Cleopatra Doumbia-Henry, President of the World Maritime University (WMU), in her talk on the topic, IMLA 40 YEARS: Maritime Education for Sustainable Shipping, ${ }^{1}$ emphasized that sustainability mindset is required at all levels of the maritime industry. She was quoted saying that "all stakeholders have a role to play, and that maritime education and training is optimally placed to reach professionals in all parts of the integrated maritime system, to affect a paradigm shift toward a global consciousness for a sustainable planet." Anchored on these propositions, the University needs to consider what the industry stakeholders have to say through an effective feedback mechanism. These can be useful in whatever decisions the institution has to make to meet stakeholders' expectations.

\section{Methods}

\section{Research Design}

The mixed-methods (Creswell 2003) using quantitative and qualitative approaches were employed in the study. Quantitative data were taken from the 
numerical information gathered from the survey. Qualitative data were derived from the respondents' answers to the open-ended questions in both the survey and the interviews.

The data were gathered mainly through a survey questionnaire designed by the University Research Council specifically for the industry stakeholders. First-hand feedback was obtained from the face-to-face interviews conducted with shipping company representatives in the actual company visits done by the University's research team every year. The data intended to discuss the factors that explain the decline in stakeholders' satisfaction were gathered through an intensive review of related literature.

\section{Respondents}

Purposive sampling (Robinson 2014) was used to determine the shipping companies visited. Four teams of representatives - each team composed of the Research Coordinator, Academic Coordinator, Shipboard Training Officer, and Placement Coordinator - were sent by the University to visit shipping companies in Manila, where the main offices are located. The weeklong company visits happen every November - a practice that started in 2011. The company representatives comprised the shipping company Presidents, Crewing Managers, and Training Officers. An average of 54 shipping companies is visited every year. Of these shipping 54 companies, 42 are included in the regular list. Each shipping company designates only one company representative to answer the survey.

\section{Research Instrument}

The survey instrument designed and adapted by the University was used to determine the industry stakeholders' level of satisfaction with the institution's quality of graduates. This instrument contained indicators or areas of competence listed as follows: Effective Communication Skills, Analytical and Critical Thinking Skills, Teamwork/Cooperation, Technological Competence, Social and ethical responsibility, Discipline, Interpersonal skills, and Loyalty, which the respondents were asked to rate based on the following scale: $8.21-10.0$ (High), 6.41 - 8.20 (Moderately High), 4.61 - 6.40 (Neutral), $2.81-4.60$ (Moderately Low), and 1.00-2.80 (Low). In the survey instrument, open spaces were also provided for the stakeholders' comments and suggestions. For the follow-up face-to-face interview with the company representatives, a set of guide questions were used.

\section{Statistical Tools}

Mean was used to describe the stakeholders' level of satisfaction, while thematic analysis was applied to categorize their specific concerns as gathered from their responses to the open-ended questions. Thematic analysis was done by first reading 
through the data, getting a feel for what is being said, and identifying key themes and issues in each text.

According to Braun and Clarke (Braun et al. 2012), thematic analysis identifies, analyzes, and reports patterns (themes) within data. It minimally organizes and describes the data that are set in rich detail. For this report, themes were drawn when key points were mentioned by at least $50 \%$ of the informants.

\section{$\underline{\text { Results }}$}

\section{Shipping Industry Stakeholders' Satisfaction}

The shipping industry has expressed a consistently moderately high level of satisfaction with the University's quality of graduates for the past nine years (2011 - 2019), as shown in Figure 1.

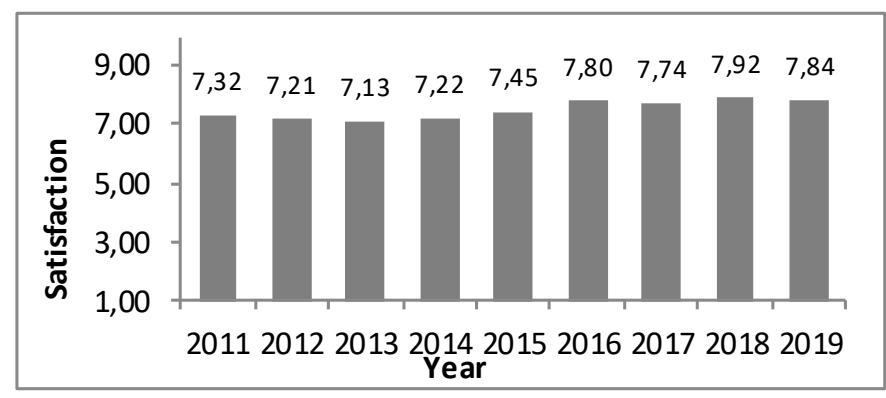

Figure 1. Level of satisfaction of the shipping industry stakeholders

Although this level of satisfaction has remained the trend over the years, a minimal decline was observed from 2011 to 2013, and a slight but steady recovery was noted from 2014 to 2016 . Then the same inclining-declining pattern was noted again from 2016 to 2019. The detailed numerical results have not pinned any extreme results as all indicators have received a moderately high rating from the industry stakeholders. However, specific areas have been identified as aspects for further improvement. These areas were mentioned in the open-ended questions and in the teams' interviews with the shipping company representatives, sorted into themes, and reported to the University Executive Council for appropriate action. These concerns are listed and discussed in Section 3.2 below.

\section{Concerns Expressed by the Shipping Industry Stakeholders}

From 2011 to 2019, the following have been the concerns expressed by the shipping company stakeholders. As mentioned earlier, thematic analysis (Braun et al. 2012) was applied to categorize these concerns as gathered from their responses to the open-ended questions. From this analysis, the following themes emerged. 


\section{Deterioration of Discipline}

Some issues on discipline that most shipping companies had repeatedly mentioned include lack of courtesy, undesirable behaviors noticed during their stay with the company offices as cadets that they carry on board, poor selfgrooming, and boastfulness/swell-headedness, lack of dedication at work, and poor conduct. Discipline is considered a serious issue by the University because it is one of its core values. To find out that some of the graduates have not exhibited this is a point worth investigating. This slack demonstration of discipline has also been identified as a challenge in other educational institutions (Benewaa 2017). Nevertheless, it remains to be one of the soughtafter characteristics that shipping companies prefer among seafarers (Retnowati et al. 2018).

\section{Poor Basic Knowledge and Skills}

Another concern from the data was inadequate communication skills for oral and written form and poor conceptual skills, especially in Mathematics, Chemistry, Physics, Navigation, and Seamanship. In the maritime curriculum, these are considered essential. There is a need to improve students' basic knowledge and skills to increase their screening advantage for company scholarships and job placements. With the increased demand for knowledgeable and highly skilled seafarers in the industry (Mitroussi et al. 2015), it is not just supplying the number of seafarers that the industry needs but producing quality and competent graduates who can be an asset to shipping companies. The students' playing cards in this competitive industry will be slim if they are deficient in the essential knowledge and skills expected of them.

\section{Poor Non-Cognitive Skills}

Zhou (2017) defined non-cognitive skills as the patterns of thought, feelings, and behaviors that are socially determined and developed throughout the lifetime to produce value. Non-cognitive skills comprise personal traits/character, attitudes, motivations, and social skills (DeAngelis et al. 2019).

The annual visits and discussions with company stakeholders highlighted their preference on the following skills: leadership, teamwork, flexibility, discipline, hard work, resilience/perseverance, loyalty, initiative, social skills (ability to use appropriate social behaviors that are pleasing to others in interpersonal situations), and adaptability that need to be developed and ingrained on maritime students in preparation for the real life on board. The needed non-cognitive skills are supported by Evidente, Estimo, Magramo, Sarinas, and Alimen (Evidente et al. 2017), who claimed that for the shipping industry to sustain itself in the years to come, it needs to have a stable fallback in terms of human resource by ensuring a steady supply of quality workforce. According to the same source, the industry needs to breed 
marine officers who possess the technical competence and skills and the soft skills to cope and survive.

\section{Medical Issues and Obesity}

Much concern is expressed on the growing number of overweight and obese cadets. This unideal weight inhibits the cadets' agility in performing physical tasks that require their muscles. This can also be a cause of frequent sickness which affects their work performance. Obesity and being overweight threaten the seafarers' health and the safety of operations onboard a ship. (Nas et al. 2014; Nittari et al. 2019; Bridger et al. 2011) Some shipping companies have also identified sexually transmitted diseases and HIV cases. The shipping companies have pointed out the crucial role of occupational health in the curriculum for maritime programs, as this has been an essential issue in the industry.

\section{Weak Safety Culture}

The standard practice of wearing complete personal protective equipment (PPE), being aware and cautious of the risks and hazards in their surroundings, paying attention to warning signs, and knowing the use of various equipment and machinery are critical safety concerns that were foregrounded. An estimated $75 \%$ to $96 \%$ of maritime casualties on board have been associated with human error (Portela et al. 2005; Uğurlu et al. 2015); hence, the culture of safety must be second nature to seafarers. Safety culture needs to be ingrained in the minds and ways of future marine officers, and it should start from the school where they are educated and trained.

\section{Factors That Explain the Decline in Stakeholders' Satisfaction}

The results shown in Figure 1 reveal some declines in the stakeholders' level of satisfaction. To provide some possible explanations for this phenomenon, a review of related literature was done to find out some possible answers of why declines in customers' level of satisfaction occur at certain points.

Adams (2013) pointed out that sometimes, the problem is not that service is worsening. The problem is that customer expectations are rising. According to her, customers form their service expectations based on their experiences across industries. Their perceptions are influenced by how they judge a company's service in comparison with other competing industries.

Maritime institutions vie to be globally competitive in keeping with the standards of the maritime industry. Shipping companies may evaluate the quality of graduates of one maritime institution based on what they have observed from other schools or from what has been passed around by word of mouth. What they may find as inferior in comparison can influence their perceptions. This implies that to sustain its competitive edge, the institution needs to evaluate its performance vis-à-vis those of other competitors in the field. Society continues to evolve, and so do the 
expectations of people. Hence, to produce quality graduates, every institution has to better itself each year to keep pace with the global trend.

Customers' personal experiences or encounters with various people and offices considered front-liners might positively or negatively affect their judgment. According to the article "Poor Staff Lead to Decline in Customer Satisfaction," more than a third of customers attributed the problem to quality of goods and services, but $29.5 \%$ attributed it to staff competence, and $21.7 \%$ to attitude ${ }^{2}$.

With competition being the talk of the industry, a mediocre staff performance made worse by an undesirable attitude towards the customers can be detrimental to the institution's image. In sustaining a positive relationship between maritime institutions and shipping company stakeholders, a strong rapport building on goodwill can dissolve prejudices often brought about by poor service or indifference. A negative impression of not being corrected over time can lead to dissatisfaction.

Another reason presented by Belleghem (2014) is the failure to focus on customer experience as a whole. According to him, when companies are divided into various departments, each department is inevitably responsible for different customer relationships. When one of the departments fails, it could create a dent in the company's whole image. Some of the top reasons for customer disloyalty are when a company overpromises and under-delivers. Rude, slovenly slow and shoddy customer experiences are another top reason. Long wait times over the phone and their call is transferred to some people making them repeat their problem, follow close behind. (Newman 2016) To solve this, total cooperation must be built among departments in the University, particularly those that directly influence or affect the education and training of cadets. Internal measures must be identified to address lapses and shortcomings because quality cannot be sacrificed for a single mistake or inadequacy committed by any office or department. A weak or defective product is reflective of a lapse in quality control, which can affect branding. Any slip-up is not just attributed to a particular flaw in the chain of process. It involves the name and integrity of the whole system. It is crucial that all members of the institution realize that how they deal with customers can make or break the institution's reputation, affecting the customers' perceptions.

\section{Action Plans to Address Stakeholders' Feedback}

In promoting continuous quality improvement, institutional review and analysis of the complaints and feedback received from stakeholders must be done annually to evaluate its performance and associated procedures. Every institution needs to engage the stakeholders, listen to their feedback, and take their concerns seriously (Fonseca et al. 2016; Grudowski et al. 2015).

One of the University's best practices is to consolidate all the feedback gathered from the stakeholders and identify priority issues by thematically analyzing the various concerns. The consolidated data are referred to significant people of the University composed of the Administrators, the Department Heads, and the Executive Council on 
top, who deliberate and accomplish the Matrix for Addressing Stakeholders' Feedback. This matrix comprises the following columns: (1) the thematized comments and suggestions of the industry stakeholders, (2) the department/area who are responsible for addressing the concern, (3) the action plans to be taken, (4) the target date of implementation of the plans, (5) the status of accomplishment which is monitored monthly until its full implementation, and (6) the list of documents/evidence of the implementation of these action plans. Issues on the deterioration of discipline are referred to the Discipline Officer and the Head of the Maritime Department, while concerns related to academics, particularly on gaps with students' cognitive and non-cognitive skills, are forwarded to the Academic Committee, who then plan on intervening measures to address the problems. A terminal evaluation of these action plans is done at the end of each academic year during the Management Review.

\section{A Process Model for Addressing Stakeholders' Feedback}

The set of surveys and interviews conducted every year undergo a work process that was tentatively tested in the first three years of its implementation but was later adopted as one of the University's best practices. This process model illustrates how the institution addresses the inputs gathered from the stakeholders to continuously improve the quality of graduates in relation to national and global standards and expectations. The steps involved in the work process are discussed below.

Step 1. Determining the level of stakeholders'satisfaction for the current year

Company visits are being done every November with various shipping companies (which include tie-up companies) in Manila to conduct the industry satisfaction survey. During the visits, feedbacks being said during the interview with shipping company Presidents or representatives are recorded and retrieved together with the survey questionnaires. All results from the survey with different groups of stakeholders are presented in graphical form to compare and identify strengths and weaknesses.

\section{Step 2. Comparing the current results with those of the previous years to detect trends and patterns}

According to Kennedy, (Kennedy 2016) detecting and learning from patterns and trends in data and processes allows organizations to improve their production processes and maintenance practices. To identify points of ups and downs and strengths and weaknesses, annual results of the stakeholders' satisfaction survey are compared side by side with those from the previous years. Trends and patterns are noted to highlight prevailing problems and repetitive issues and concerns.

\section{Step 3. Identifying the gaps and opportunities for improvement}

Based on the comparative analyses done every year, gaps and opportunities for improvement are identified. Such data are used to identify problematic areas and design 
new plans for corrective action and continuous improvement. Through gap analysis, areas for improvement can be identified, and strategies or interventions to bridge the gap between actual and expected outputs can be collectively panned out. (Peterson 2019)

\section{Step 4. Thematizing the common issues and concerns reported by the stakeholders \\ Aside from the numerical data representing the stakeholders' level of satisfaction, some issues emerge from their answers to the open-ended questions in the survey questionnaire and the discussions during the interview. Although their responses vary in how they express them, they point to common issues and concerns mentioned in the data. It is the task of the Research Department of the University to process these qualitative data and group them into categorical themes.}

Step 5. Referring the stakeholders'feedback to concerned areas or departments

In addition to the numerical data, the thematized results are reported to the Administrators, depending on where the concerns are based. This system is done by addressing the report to the Department Heads, who are then tasked to include the feedback in their departmental meetings and operation plans. At the university level, issues or concerns that are found common in all campuses are consolidated and reported to the Executive Council headed by the Chief Executive Officer for appropriate action (Also discussed in 3.4).

Step 6. Deliberating on what actions to take to address the issues and concerns

Getting actionable data can benefit companies in that they can generate collective ideas in addressing issues and concerns raised by the stakeholders or customers to improve their image. (Quinncy 2015) The feedback collected and the concerns and issues raised, if adequately addressed, can help create better customer service, and consequently, better stakeholders' satisfaction. In this step of the process model, the department to which the feedback was referred begins to deliberate how the concerns can be promptly and adequately addressed. The plans of action are prepared in response to the feedback received. Such plans become part of the current year's departmental goals.

\section{Step 7. Implementing the action plans}

The action plans take form as the concerned departments work to accomplish them the soonest time possible (the current year during which the feedback was referred to them). All actions taken are adequately documented for record purposes. Measures are done to ensure that these actions address the feedbacks that were referred to the department. According to Josh Bersin, (Joshbersin 2019) feedback systems must be sound enough to send actionable nudges, alerts, advice, and tips to leaders and their teams. All words without action will not yield concrete solutions. 
Action plans show what objectives you need to set, what concrete plans you need to lay down, who will be responsible for them, how long it will take to have the plans realized, and what resources will be needed to actualize them. Action plans also need to be monitored regularly and evaluated by the end of the timeline set.

\section{Step 8. Evaluating the status of the actions taken}

By the end of each school year, the department evaluates the status of the action plans. An accomplishment report is submitted to the Executive Council of the University.

An identical copy of the report is provided to the Research Office who organizes all the documents into a file with all the attached evidence.

\section{Step 9. Providing the stakeholders updates on how the institution addressed their concerns}

As soon as the feedback from the stakeholders has been addressed, a communication is sent to shipping companies by the CEO himself informing them that their feedback had already been acted upon. They are also provided a copy of the University's accomplishments based on the concerns that they had raised.

Figure 2 shows the flow of the process model as discussed.

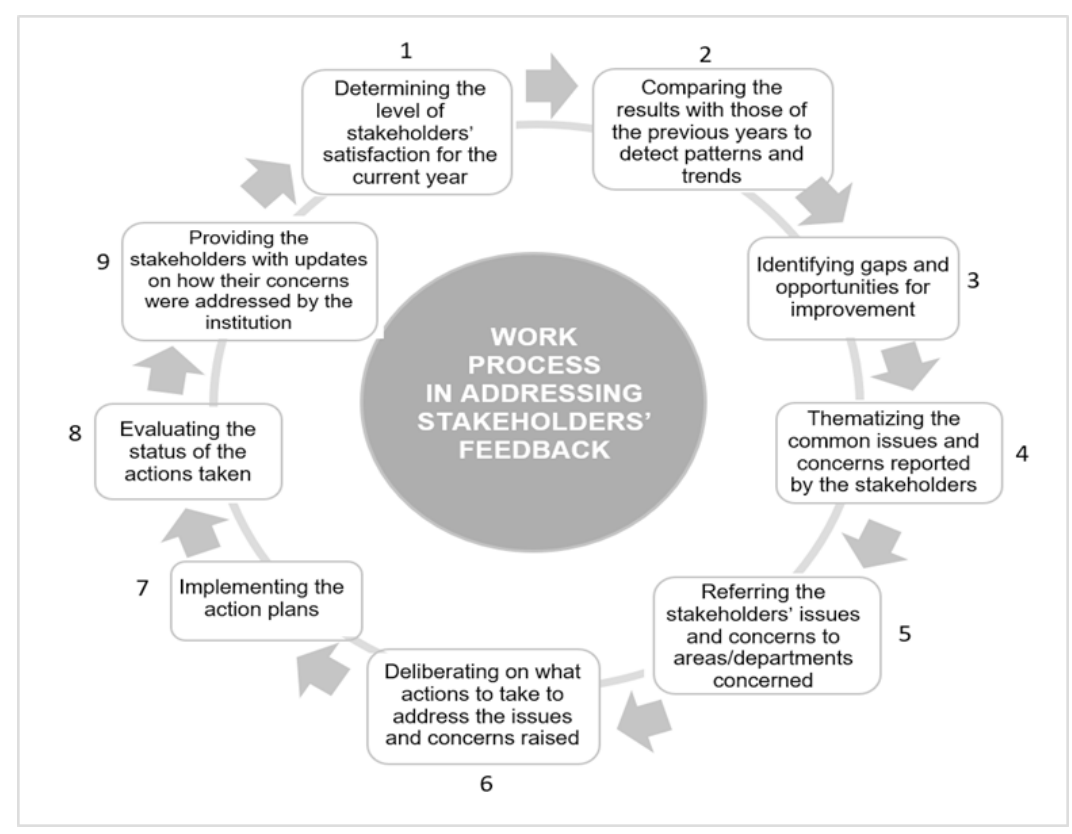

Figure 2. A Process Model for Addressing Stakeholders' Feedback 


\section{Conclusions and implications}

This analysis revealed a trend in the level of satisfaction of the University's stakeholders, which points to a moderately high level of satisfaction. This satisfaction level occasionally experiences some drawbacks due to certain factors; yet, it quickly recovers as the institution has been steadily vigilant in gathering and recording stakeholders' feedback and acting on the concerns that they have raised before matters get worse. The annual stakeholders' satisfaction survey has proven itself an effective mechanism to track its performance vis-à-vis stakeholders' expectations.

Certain factors have been identified as possibly influential in the decline of the stakeholders' satisfaction. One theory is that the problem is not that the school's services are worsening; the customers' expectations are rising. Maritime Higher Education Institutions (MHEIs) are expected to keep pace and cope with these growing demands and expectations with the maritime and business industries being so competitive. With all the educational institutions trying to catch up in proving their capability and capacity to provide world-class graduates, being competitive has become the talk of the industry. Where there is competition, stakeholders are provided with a point of comparison to select which schools to seek after. The stakeholders can select institutions that could offer them a good benchmark for "quality graduates" and deliver the most efficient service. Anything that falls short of their expectations can be equivalent to a decline in their level of satisfaction.

The work processes to address stakeholders' feedback and concerns are in place and are working well. The administration has considered it as one of its best practices. Stakeholders are also provided updates regarding courses of action taken by the University to address their concerns. The University is continuously maximizing all strategies possible to sustain its performance in meeting stakeholders' expectations.

The University needs to continuously improve the quality of graduates that it produces by strengthening its physical facilities and resources, enhancing the academic education and training provided to students, and improving the quality of services offered to its customers/clients through its frontliners. Further investigation and analysis may focus on feedback from other groups of stakeholders such as the students, parents, alumni, and the employees, aside from the industry.

\section{NOTES}

1. IMLA 40 Years: Maritime Education for Sustainable Shipping. December 15, 2020. Available from: https://www.wmu.se/news/imla-40-years-maritimeeducation-for-sustainable-shipping. 
2. Institute of Customer Service (ICS), 2015. Poor Staff Lead To Decline In Customer Satisfaction With Car Manufacturers. Engage Customer [June 1, 2015]. Available from: https://engagecustomer.com/poor-staff-lead-to-declinein-customer-satisfaction-with-car-manufacturers/.

\section{REFERENCES}

Ackermann, F. \& Eden, C., 2011. Strategic Management of Stakeholders: Theory and Practice. Long Range Planning. 44(3), 179 - 196. Available from: https://doi.org/10.1016/j.lrp.2010.08.001.

Adams, S., 2013. How To Deal With A Younger Boss. Forbes [May 30,2013]. Available from: https://www.forbes.com/sites/susanadams/2013/05/30/ how-to-deal-with-a-younger-boss-2/.

Belleghem, S. Van, 2014. Five Reasons Customer Loyalty Is Decreasing - and What You Can Do about It. Text. MyCustomer [October 8, 2014]. Available from: https://www.mycustomer.com/experience/ loyalty/five-reasons-customer-loyalty-is-decreasing-and-what-youcan-do-about-it.

Benewaa, B., 2017. Student Disciplinary Challenges in Obuasi Secondary Technical School. Thesis. University of Education, Winneba. Available from: http://ir.uew.edu.gh/xmlui/handle/123456789/967.

Braun, V. \& Clarke, V., 2012. Thematic Analysis. In: APA Handbook of Research Methods in Psychology 2: Research Designs: Quantitative, Qualitative, Neuropsychological, and Biological, 57 - 71. APA Handbooks in Psychology. Washington, DC, US: American Psychological Association. Available from: https://doi.org/10.1037/13620-004.

Bridger, R. S., \& Bennett, A. I., 2011. Age and BMI Interact to Determine Work Ability in Seafarers. Occupational Medicine. 61(3), 157 - 162. Available from: https://doi.org/10.1093/occmed/kqr003.

Creswell, J. W., 2003. An Introduction to Mixed Methods Research, 43 [March, 2007].

DeAngelis,C.A.,2019.DivergencesbetweenEffectsonTestScoresandEffects on Non-Cognitive Skills. Educational Review, 1 - 12 [August 5, 2019]. Available from: https://doi.org/10.1080/00131911.2019.1646707.

Evidente, L. G., Estimo, E., Magramo, M. M., Sarinas, B. \& Alimen, R., 2017. A Model Towards Developing Life Skills Among Maritime Students For Longer Service At Sea.

Fassin, Y., 2009. The Stakeholder Model Refined. Journal of Business Ethics. 84(1), 113 - 135. Available from: https://doi.org/10.1007/s10551008-9677-4.

Fonseca, L., Ramos, A., Rosa, A., Ana Braga, C., \& Sampaio, P., 2016. Stakeholders Satisfaction and Sustainable Success. International Journal 
of Industrial and Systems Engineering. 24(2), 144 - 157. Available from: https://doi.org/10.1504/IJISE.2016.078899.

Freeman, R. E., 2015. Stakeholder Theory. In: Wiley Encyclopedia of Management, 1 - 6. American Cancer Society. Available from: https:// doi.org/10.1002/9781118785317.weom020179.

2010. Strategic Management: A Stakeholder Approach. Cambridge University Press.

Grudowski, P. \& Pawe, J., 2015. Stakeholders Satisfaction Index as an Important Factor of Improving Quality Management Systems of Universities in Poland, 12.

Joshbersin, 2019. Employee Engagement 3.0 - From Feedback to Action. [JOSH BERSIN, April 14, 2019]. Available from: https://joshbersin. com/2019/04/employee-engagement-3-0-from-feedback-to-action/.

Kennedy, S., 2016. Trends Are Telling: Detecting and Learning from Patterns and Trends in Data. Plant Services [October 4, 2016]. Available from: https:/www.plantservices.com/articles/2016/technology-toolbox-trendsare-telling/.

Mitroussi, K. \& Notteboom, T., 2015. Getting the Work Done: Motivation Needs and Processes for Seafarers and Dock Workers. WMU Journal of Maritime Affairs 14(2), 247 - 265. Available from: https://doi. org/10.1007/s13437-014-0064-y.

Nas, S. \& F1şkın, R., 2014. A Research on Obesity among Turkish Seafarers. International Maritime Health 65(4), 187 - 191. Available from: https:// doi.org/10.5603/IMH.2014.0036.

Newman, E., 2016. Understanding Customer Disloyalty. Yonyx [April 20, 2016]. Available from: https://corp.yonyx.com/customer-service/ understanding-customer-disloyalty/.

Nittari, G., Tomassoni, D., Di Canio, M., Traini, E., Pirillo, I., Minciacchi, A. \& Amenta, F., 2019. Overweight among Seafarers Working on Board Merchant Ships. BMC Public Health 19(1), 45. Available from: https:// doi.org/10.1186/s12889-018-6377-6.

Peterson, O., 2019. Gap Analysis: How to Bridge the Gap Between Performance and Potential. Process Street. Checklist, Workflow, and SOP Software [July 19, 2019]. Available from: https:/www.process.st/gap-analysis/.

Portela, Rosa de la Campa, 2005. Maritime Casualties Analysis as a Tool to Improve Research about Human Factors on Maritime Environment. Journal of Maritime Research 2(2), 3-18.

Quinncy, F., 2015. Top Four Ways in Which Customer Feedback Helps an Organization. LiveAdmins [March 6, 2015]. Available from: https:// www.liveadmins.com/blog/top-four-ways-in-which-customer-feedbackhelps-an-organization/. 
Retnowati, E. Ghufron, A., Marzuki, Kasiyan, Pierawan, A.C. \& Ashadi, 2018. Character Education for 21st Century Global Citizens. In: Proceedings of the 2nd International Conference on Teacher Education and Professional Development (INCOTEPD 2017) [October 21 - 22, 2017]. Yogyakarta, Indonesia: Routledge.

Robinson, R. S., 2014. Purposive Sampling. In: Encyclopedia of Quality of Life and Well-Being Research. Edited by Alex C. Michalos, $5243-$ 5245. Dordrecht: Springer Netherlands. Available from: https://doi. org/10.1007/978-94-007-0753-5_2337.

Uğurlu, Ö., Yildirim, U. \& Başar, E., 2015. Analysis Of Grounding Accidents Caused By Human Error. Journal of Marine Science and Technology [October 28, 2015].

Ulewicz, Robert, 2017. The Role Of Stakeholders In Quality Assurance In Higher Education. Human Resources Management and Ergonomics 11, $93-107$.

Zhou, K., 2017. Non-Cognitive Skills: Potential Candidates for Global Measurement. European Journal of Education. 52(4), 487 - 497. Available from: https://doi.org/10.1111/ejed.12241.

Emeliza T. Estimo

John B. Lacson Colleges Foundation Alijis, Bacolod City, Philippines E-mail: emeliza.estimo@jblfmu.edu.ph

$\triangle$ Geneveve M. Aguilar

John B. Lacson Colleges Foundation Alijis, Bacolod City, Philippines E-mail: geneveve.aguilar@jblfmu.edu.ph 